\title{
The Semantics of Case in Russian Secondary Predication
}

\author{
Hana Filip \\ Northwestern University
}

\section{Introduction}

Secondary predicates in Russian are in the instrumental case (INST), or they agree in case (AGR) with their controlling argument in the main clause. The selection of case morphology depends on a complex interaction of a number of factors. ${ }^{1}$ Here, the focus is only on semantic factors that have direct theoretical implications for the individual-level predicate (ILP) vs. stage-level predicate (SLP) distinction. I analyze the semantic constraints on ILPs used as depictives, situation anchors, and restrictors in sentences expressing quantification over situations, that is, in contexts in which they appear to have SL interpretations. I will advance three main claims: First, ILPs in Russian do not here undergo a shift into SLPs, but rather retain their inherent IL status. Second, case morphology on Russian predicates does not encode the $\mathrm{IL}$ and SL status of predicates. Third, the ILP-SLP distinction cannot be temporally-based, as Carlson (1977) originally proposed. My exploration of this topic involves the interactions among morphological case, the situation-related structure and the quantificational structure of sentences.

\section{Data and Main Questions}

Semantic effects of the INST-AGR alternation on depictives can be illustrated by pairs like those in (1a,b) (from Nichols 1981, p. 156, including her judgements).

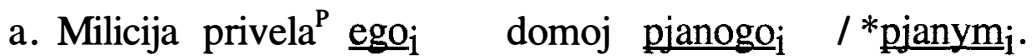
police brought him.ACC home drunk.ACC / *drunk.INST
'The police brought him home drunk.'
b. Druz'ja priveli ${ }^{\mathrm{P}} \mathrm{eg}_{\mathrm{i}}$ domoj, \#pjanogo $\mathrm{j}_{\mathrm{i}} /$ pjanym $_{\mathrm{i}}$.
friends brought him.ACC home drunk.ACC/drunk.INST
'His friends brought him home drunk.'

In $(1 \mathrm{a}, \mathrm{b})$ the depictive 'drunk' characterizes the individual denoted by the controlling DO-argument in relation to the situation time of the main predicate: i.e., he was drunk at the time when he was brought home. In (1a), the depictive pjanogo agrees in the accusative case with its controlling DO-argument 'him', while in (1b) the depictive is in the INST case pjanym and entails a change, namely that 'he' went from a state of sobriety to drunkenness before being brought home (see Nichols 1981, p.156, 252). In contrast, (1a) carries no suggestion of a change.

The SLP 'drunk' is of the appropriate semantic type to satisfy the basic semantic constraint on depictives that they express a (potentially) transitory property of their host argument in the main clause. (For the origins of this constraint see Bresnan 1982, Rothstein 1983, Section 5.1, and references therein.) Intuitively, a depictive temporally contains, and thus temporally locates, the situation time of a main predicate. SLPs are ideal depictives, because they denote sets of temporally and spatially bounded stages of individuals (Carlson 1977). ILPs are often odd or excluded as depictives, because they describe properties that hold atemporally (or at any time) of their arguments (Carlson 1977). Hence, asserting that the situation time of an ILP depictive contains the situation time of the main predicate is always true, which means 
that it is utterly uninformative (see also Stump 1985, Ch. VI. 2.2.1. for similar observations): cp. Ivan worked blue-eyed.

However, ILPs can function as depictives, provided the main clause supports a reading of an ILP depictive as involving a change with respect to the property that the ILP depictive describes (see McNally 1993, and Section 3.2. below). In Russian, this interpretation must be overtly encoded by the INST case on ILPs used as depictives. As (2) shows, only the INST-form of the nominal ILP 'murderer' is sanctioned, but not the AGR-form, here NOM. (2) is most naturally taken to mean that something must have happened in the room to make him a murderer. The particular type of a change is indeterminate; depending on the context, he may have murdered somebody, been convicted a murderer, etc.

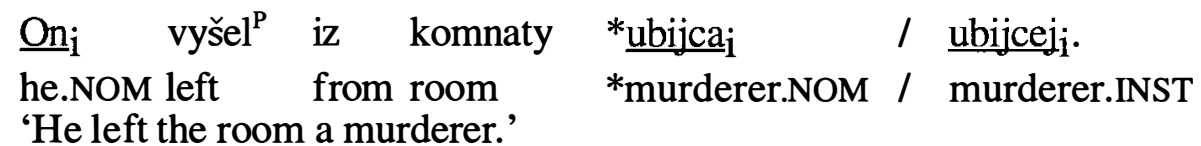

Secondary predicates used as, what I call, 'situation anchors' specify a single situation in which one or more occurrences of a situation of the type described by the main predicate holds. Situation anchors roughly correspond to ordinary temporal when-clauses or temporal as-clauses. For example, in (3a), taken from Nichols (1981, p.42), the SLP 'sleeping' delimits a single situation in which 'he could not forget about it' holds (under one of the readings of (3a)).

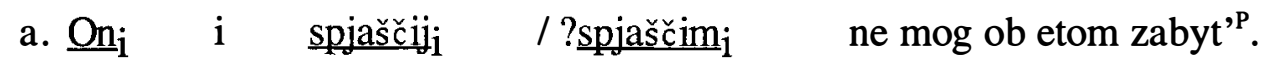
he.NOM even sleeping.NOM/ ?sleeping.INST NEG could about it forget 'He couldn't forget about it, even when he was sleeping.'

$\begin{array}{lll}\text { b. *Golodnyj } & \text { / golodnym } \\ \text { *hungry.NOM / hungry.INST } & \underline{\text { he }}_{\mathrm{i}} \text { vozvraščalsja' }^{\text {I }} \text { returned } & \text { domoj. } \\ \text { 'When(ever) he was hungry, he returned home.' } & \text { home }\end{array}$

Secondary predicates can also form the restrictive clause of various sentential operators: e.g., iterative, generic, deontic, epistemic, and counterfactual, for example. In (3b), the SLP 'hungry' serves as a restrictor of an implicit (phonologically null) generic operator. (3b) can be then paraphrased as 'Generally, if there was a situation of him being hungry, he returned home in such a situation.' Secondary predicates as restrictors in sentences with generic quantification roughly correspond to atemporal when-clauses (Carlson 1979), restrictive if/when-clauses (Farkas and Sugioka 1984), or restrictive as-clauses in English (Katz 1993). Notice that SLPs used as situation anchors preferably agree with their host argument (3a), while SLPs used as restrictors must be in the INST case (3b).

In Russian, ILPs may also function as situation anchors and restrictors, provided they are in the INST case, as is shown in (4). (4)/(i) illustrates the situation anchor reading of nominal ILPs: 'Teacher' here delimits a single situation in which 'he was often ill' holds, and hence it appears to be of a SL type.

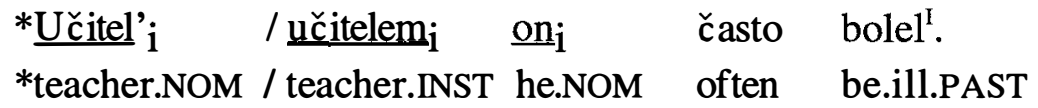

(i) 'When he was a teacher, he was often ill.' / 'As a teacher, ...'

(ii) 'He was often ill if/when(ever) he was a teacher.' / 'As a teacher, ...'

ILPs may also serve as restrictors of quantificational operators. The interpretation of (4) may involve an implicit generic quantifier, whereby the ILP 
'teacher' contributes the restrictive clause for the sentential quantification over situations. The meaning of (4) then corresponds to the translation in (4)/(ii), and it can be paraphrased as 'Generally, if there was a situation of him being a teacher, he was often ill in such a situation.' The observation that ILPs can be interpreted as forming the restrictive clause in sentential quantification over situations, rather than individuals, has so far not been given enough attention in quantificational studies. It represents an atypical case from the point of view of the prototypical expression of quantification and quantificational ontology, as discussed by Partee (1991a). If the domain of quantification involves situations, the main sortal predicate for the relevant quantificational operator is typically provided by a $S L P$, and not an ILP.

Table I summarizes the data presented so far. (Nominal) ILPs are restricted to occur in the INST case in all their uses as secondary predicates, while SLPs require the INST case only if they are used as restrictors of quantifiers.

Table I: AGR-INST alternation on secondary predicates

\begin{tabular}{|l|c|l|c|c|c|c|}
\hline & \multicolumn{2}{|c|}{ depictives } & \multicolumn{2}{c|}{ situation anchors } & \multicolumn{2}{c|}{ restrictors } \\
\hline & AGR & INST & AGR & INST & AGR & INST \\
\hline SLP & $\sqrt{ }$ & $? / \sqrt{ }$ & $\sqrt{ }$ & $? / \sqrt{ }$ & $*$ & $\sqrt{ }$ \\
\hline ILP (nominal) & $*$ & $\sqrt{ }$ & $*$ & $\sqrt{ }$ & $*$ & $\sqrt{ }$ \\
\hline
\end{tabular}

The main questions I pose are as follows:

1. How do we motivate the observation that ILPs in the INST case occur in contexts in which SLPs are typically expected, namely, as depictives, situation anchors and restrictors?

2. Why do SLPs used as restrictors require the INST case, but when used as depictives and situation anchors they do not require it?

3. What does the behavior of ILPs in the INST case, which appear to have SL properties, tell us about the nature of the ILP-SLP distinction?

\section{The Semantics of the Instrumental-Agreement Alternation}

\subsection{Cases as Overt Exponents of the IL and SL Status of Predicates}

It might be tempting to propose that a combination of an ILP and the INST case is a SLP, and therefore it is not surprising to find ILPs in the INST case in contexts in which SLPs freely occur. In fact, a proposal along these lines exists. Let me call it the 'Null-Hypothesis', and state it in the most general terms in (5):

(5) Null-Hypothesis: In Russian, the semantic type of a (nominal or an adjectival) predicate is formally marked by case morphology. A predicate describes

(a) a permanent property, if(f) it is in the AGR case, and therefore it is an ILP;

(b) a temporary property, if(f) it is in the INST case, and therefore it is a SLP.

The Null-Hypothesis says that all case-marked predicates in Russian are either ILPs or SLPs. Among those who most recently subscribe to it, albeit only with respect to primary predicates, are Geist (1999), Pereltsvaig (1999), and Becker (2000) who applies it in acquisition studies. The Null-Hypothesis has its roots in traditional descriptive and reference grammars, where INST-predicates are characterized as describing properties that are temporally limited, transitory, episodic, changeable, accidental, inessential, or locatable in time and space. In contrast, AGR-predicates are taken to have a stative meaning and to express a descriptive background for other 
events, or used for properties that are permanent, essential, and independent of particular time points and locations. Timberlake (1982, p.323ff.), who only discusses examples with predicative nouns, observes that INST is preferred, if some temporal or also modal limitation is imposed on the property described by a nominal predicate.

The Null-Hypothesis given in (5) is compatible with the idea that nominal and adjectival predicates are classified as ILPs or SLPs not in the lexicon, but rather after the postlexical case assignment to them (see Geist 1999, p.18). Another way of implementing the Null-Hypothesis would be to treat morphological cases as overt markers of coercion functions that induce shifts between ILPs and SLPs. In English, the coercion mechanism is often evoked for situations in which inherent ILPs are felicitously used in contexts that license SLPs, for example (e.g., Kratzer 1989, 1995). On this view, the Russian INST case could be semantically characterized as a function that coerces inherent ILPs into SLPs, and the AGR cases as functions that map inherent SLPs into ILPs.

One of the goals of this paper is to establish that the Null-Hypothesis given in (5) is wrong, regardless in which way it may be implemented. The claim that INSTpredicates are uniformly SLPs is clearly invalidated by the standard diagnostic tests for SLPs proposed by Carlson (1977) and (1982). He observes that temporary interpretations of ILPs that are intended to hold at particular time points and locations are generally impossible or at least odd $(6 a, c)$, while SLPs are perfectly acceptable when interpreted in this way $(6 \mathrm{~b}, \mathrm{~d})$. (Examples in (6) are taken from Kratzer (1995, p.128, see also 1989) and slightly modified.) We observe the same differential behavior of Russian ILPs and SLPs with respect to locative and time-point adverbials, as examples in (7) show. In (7a) 'hungry' in the NOM case is compatible with the modifiers at seven o'clock and in the garden, which means that it behaves like a SLP, and not an ILP, contrary to the Null-Hypothesis given in (5). In (7b) 'teacher' in the INST case is odd with these modifiers, which indicates that it behaves like an ILP, and not a SLP, contrary to (5).
a. ?Manon is a dancer on the lawn.
c. ?Manon is a dancer at $7 \mathrm{pm}$.
b. Manon is dancing on the lawn.
d. Manon is dancing at $7 \mathrm{pm}$.

a. Boris ${ }_{i}$ byl golodnyji / golodnym $j_{i}$ v sem časov / v sadu. Boris.NOM was hungry.NOM / hungry.INST at seven o'clock/in garden 'Boris was hungry at seven o'clock / in the garden.'
b. $\underline{\text { Boris }} \mathbf{i}$
byl učitel'i
$/ \underline{u c ̌ i t e l e m}_{\mathbf{i}}$
?v sem časov
/ ?v sadu.
Boris.NOM was teacher.NOM / teacher.INST ?at seven o'clock / ?in garden 'Boris was a teacher ??at seven o'clock / ??in the garden.'

The Null-Hypothesis would also make the wrong predictions for the behavior of secondary predicates. For example, if we also assume the SLP constraint on depictives (see Section 1., ex. $(1 \mathrm{a}, \mathrm{b})$ ), it would follow that only predicates in the INST case are licensed as depictives, because all and only predicates in the INST case are SLPs, whereas predicates in the AGR cases ought to be excluded, because they are uniformly ILPs. However, this is contradicted by examples in (8a) and (8b), taken from Hinterhölzl (2000) and Nichols (1981, p.84), respectively. (8a) with the depictive 'intelligent' in INST is odd, but with 'well-educated' also in INST it is wellformed. (8b) is well-formed, although its depictive 'wrapped' occurs in the NOM case, the AGR case. (9) is odd, due to the incompatibility of the depictive 'child' with the time-point and locative modifiers, which indicates that 'child' retains its inherent $\mathrm{IL}$ status even though it is in INST. This again contradicts the Null-Hypothesis given in (5). However, it is correctly predicted by (5) that $\underline{\mathrm{Ja}}_{i}$ vstretil $\underline{\text { ego }}_{j} \underline{\text { rebenkom }}_{i / j}$ - 'I met him when I/he was a child<INST>' on its own is well-formed, because the depictive 'child' in INST is a SLP, according to (5). 


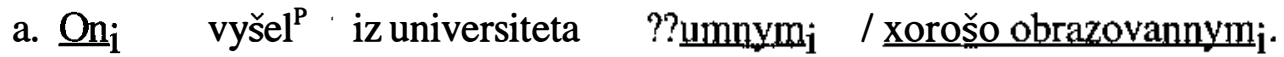
he.NOM left from university ??intelligent.INST / well-educated.INST 'He came out of the university ??intelligent / well-educated.'
b. $\underline{S y r}_{i} \quad$ ležal ${ }^{I}$ zavernutyj $\dot{j}_{i} \quad \mathrm{v}$ bumagu. cheese.NOM lay wrapped.NOM in paper

'The cheese lay wrapped in paper.'

(9) $\underline{\mathrm{J}}_{\mathrm{i}} \quad$ vstretil $^{\mathrm{P}} \underline{\text { ego }}_{\mathrm{j}} \quad \underline{\text { rebenkom }}_{\mathrm{i} / \mathrm{j}} /$ pjanym $_{\mathrm{i} / \mathrm{j}} \quad \mathrm{v}$ sem časov / v sadu. I.NOM met him.ACC ?child.INST / drunk.INST at seven o'clock / in garden 'I met him when I/he was ?a child / drunk at seven o'clock / in the garden.'

To summarize, examples in (7) and (9) show that time-point and locative modifiers interact with the inherent IL and SL status of predicates and not their morphological case form. Crucially, SLPs in the NOM-case retain their SLP status and ILPs in the INST-case retain their ILP status. We obtain the same results with respect to other diagnostic tests for the ILP-SLP distinction proposed by Carlson (1977, 1982), to the extent that they are applicable to Russian. (8a) shows that morphological case is insufficient as a predictor of the acceptability of ILPs as depictives. Although I cannot provide further evidence, due to the space limitation, this ought be sufficient for concluding that morphological cases in Russian do not determine the $\mathrm{IL}$ and SL status of predicates, and therefore the Null-Hypothesis given in (5) must be rejected.

In addition, the Null-Hypothesis is problematic on general theoretical grounds. Although it might appear compelling without a detailed scrutiny, it has wide-reaching undesirable consequences for the ILP-SLP distinction and the parts of grammar where this distinction is relevant. For example, one area regards quantification and the N-V distinction. In Russian, argument positions can be filled by quantified DPs in the INST case (e.g., Ja vstretilas' s každoj devočkoj - 'I met every girl'). Generally, quantifiers that syntactically appear inside DPs in argument positions do not behave like adverbial quantifiers, therefore, we do not expect SLPs, but rather ILPs, to form the range of a quantifier, where the head nominal ILP is the principal sortal predicate. Quantified DPs are a natural locus of quantification over individuals. This means that if we wanted to uphold the Null-Hypothesis, we would want to restrict the claim that nominal ILPs in the INST case are SLPs only to nouns used as predicates, but not as arguments. This move would effectively split Russian nouns into ILPs and SLPs, either in the lexicon or postlexically. But this would raise the question about the basic $\mathrm{N}-\mathrm{V}$ distinction in Russian, and whether it significantly differs from the N-V distinction in English, where nouns are taken to be ILPs (both as arguments and predicates) and most verbs are SLPs, as Carlson (1977) original proposed. We may also want to ask whether there are other languages in which the ILP-SLP distinction is encoded by cases on nouns and if so, try to formulate cross-linguistic generalizations in this domain.

\subsection{Proposal: Independence of Cases and IL-SL Type of Predicates}

(10) a. In Russian, the IL or SL type of predicates is not formally encoded by case morphology.

b. The INST case is the marked form in the INST-AGR alternation on predicates, and it contributes the meaning of a 'change' with respect to the property described by the predicate to which it is applied. This is understood as meaning that INST denotes a set of pairs of situations $\left\langle s_{1}, s_{2}\right\rangle$, such that (i) the 
truth of $P\left(s_{1}\right)$ entails the falsity of $P\left(s_{2}\right)$, and vice versa; (ii) the running time of $\left(s_{1}\right)$ strictly precedes the running time of $\left(s_{2}\right)$.

c. The AGR case is unmarked, which means 'not necesssarily' conveying the meaning component of a 'change'.

The idea that INST is the marked case in the INST-AGR alternation on predicates is mainly based on Jakobson (1936/1971). I will argue that the semantics of the INSTAGR alternation on predicates is orthogonal to the ILP-SLP distinction. In particular, the temporal notion of a 'change' is logically compatible with both SLPs and ILPs, because it can co-occur with both types of predicates (see also Fernald 1994/2000). It is also logically independent of both SLPs and ILPs, because it need not co-occur with either of them.

\section{Case and Secondary Predication}

First, I will apply the core proposal given in (10) to the easiest cases, namely, to sentences with SLP depictives. Then I will discuss the more complicated examples of ILP depictives. Finally, I will show how my analysis extends to the uses of secondary predicates as situation anchors and restrictors on quantifier domains.

\subsection{SLP Depictives}

As far as the semantic analysis of depictives is concerned, I assume Rothstein's (2000) proposal, which in a slightly modified version is given in (11):

(11) The situation described by the main clause $\left(s_{1}\right)$ must be PART-OF the situation introduced by the secondary predicate $\left(s_{2}\right)$. The PART-OF relation is characterized as follows:

a. Temporal dependency constraint: The situation time of $s_{1}$ is temporally contained in the situation time of $s_{2}: \tau\left(s_{1}\right) \leq \tau\left(s_{2}\right)$.

b. Shared grammatical argument constraint: $s_{1}$ and $s_{2}$ share a participant.

The temporal dependency constraint in (11a) licenses the relation between the main predicate and depictive through the situation argument of the two predicates. Rothstein treats the depictive predication as involving an operation that sums the denotation of the main and the secondary predicate. (For the summing operation see Lasersohn 1992.) This presupposes that the domain of situations has a mereological structure that is (partially) ordered by the part relation ' $\leq$ ': $\forall \mathrm{x}, \mathrm{y} \in \mathrm{U}[\mathrm{x} \leq \mathrm{y} \leftrightarrow \mathrm{x} \oplus \mathrm{y}=\mathrm{y}]$, where ' $\oplus$ ' is a binary sum operation. (See Bach 1981, 1986, Krifka 1986, 1992, 1998, Lasersohn 1992.) The situation variable $s$ ranges over situations, and the domain of situations $S$ is a union of the set $S$ of states, the set $P$ of processes and the set $E$ of events: $S=S \cup P \cup E$. The temporal trace function $\tau$ assigns to each situation $s$ the time $t$ that $s$ takes up, such that $\forall \mathrm{s}^{\prime} \mathrm{s}^{\prime}\left[\tau\left(\mathrm{s}^{\prime} \oplus \mathrm{s}^{\prime}\right)=\tau(\mathrm{s}) \oplus \tau\left(\mathrm{s}^{\prime}\right)\right]$. (For any two situations $s$ and $s$ ', the sum of their temporal traces equals the temporal trace assigned to the sum of these situations (additivity), provided the two situations do not temporally overlap: $\forall s, s^{\prime} \neg\left[\tau(s) \otimes \tau\left(s^{\prime}\right)\right] . ~ ' \otimes$ ', is the overlap relation: $\forall x, y, z \in U[x \otimes y \leftrightarrow \exists z \in U[z \leq x \wedge$ $\mathrm{z} \leq \mathrm{y}]$ ]. For the above definitions see also Krifka 1992 and 1998.)

On my analysis it is expected that SL depictives will alternate between AGR and INST case forms, because inherent SLPs retain their SL property in all case forms, as I have argued in Section 2.1. The selection of the appropriate case is 
governed by the general semantic properties of cases on predicates, as proposed in $(10 b, c)$. For example, in (12) the INST-depictive 'drunk' is used to convey that the individual denoted by its controlling subject argument became drunk, while the AGR/NOM-depictive 'drunk' is unmarked in this respect, and it may describe a stage of being drunk. Since the stage of being drunk is temporally and causally closely related to the change from sobriety to drunkenness, native speakers do not here perceive a significant difference between the semantic contributions of the AGR/NOM and the INST forms of the depictive, and the two forms alternate without affecting the well-formedness of the whole sentence.

\section{$\underline{O n}_{i} \quad \check{z ̌ e n i l s j a ~}^{\mathrm{P} / \mathrm{I}}$ na nej pjanyji $\mathrm{j}_{\mathrm{i}} \quad$ pjanym $_{\mathrm{i}}$. Hinterhölzl 2000 he.NOM married on her drunk.NOM / drunk.INST 'He married her (having gotten) drunk.'}

More intriguing are examples in which native speakers perceive a clear difference between the contributions of the INST or AGR depictives, or in which either the INST-depictive or the AGR-depictive is strongly preferred, or even the only possible form. Following Nichols' $(1981$, p.156, 252) comments, our initial example (1b) differs from (1a) in entailing a change with respect to the property described by the depictive 'drunk'. (1a) and (1b) can be assigned the logical forms given in (13a) and (13b), respectively. In (13b) the meaning of 'change' contributed by the INST case to the SLP 'drunk' is represented in terms of a reversal of the truth of the predicate: $\neg$ drunk $\left(\right.$ he,$\left.s_{2}\right) \wedge \operatorname{drunk}\left(\right.$ he,$\left.s_{3}\right)$.

$$
\text { a. } \begin{aligned}
\exists & s s_{1} \exists s_{2}\left[s=s_{1} \oplus \dot{s}_{2} \wedge \text { bring-home }\left(\text { friends, he, } s_{1}\right) \wedge \text { drunk }\left(\text { he, } s_{2}\right)\right. \\
& \left.\wedge \tau\left(s_{1}\right) \leq \tau\left(s_{2}\right)\right]
\end{aligned}
$$

b. $\exists s \exists s_{1} \exists s_{2} \exists s_{3}\left[s=s_{1} \oplus s_{3} \wedge\right.$ bring-home(friends, he, $\left.s_{1}\right)$

$$
\wedge\left[\neg \operatorname{drunk}\left(\text { he, } s_{2}\right) \wedge \operatorname{drunk}\left(\text { he }, s_{3}\right) \wedge \operatorname{BEFORE}\left(\left(\tau\left(s_{2}\right), \tau\left(s_{3}\right)\right)\right] \wedge \tau\left(s_{1}\right) \leq \tau\left(s_{3}\right)\right]
$$

In general, I propose that INST is a modifier of predicates (and their arguments) that denotes a set of pairs of situations, as specified in (14):

(14) INST denotes a set of pairs of situations $\left\langle\mathrm{s}_{1}, \mathrm{~s}_{2}\right\rangle$, such that

(i) the truth of $\mathrm{P}\left(\mathrm{s}_{1}\right)$ entails the falsity of $\mathrm{P}\left(\mathrm{s}_{2}\right)$, and vice versa;

(ii) $\tau\left(s_{1}\right)$ strictly precedes $\tau\left(s_{2}\right)$ : $\operatorname{BEFORE}\left(\left(\tau\left(s_{1}\right), \tau\left(s_{2}\right)\right)\right.$.

I assume that logical operators like negation and various adverbial modifiers introduce operations over situation descriptions, where an atomic situation description is a verbal predicate with all its argument positions filled by variables or constants (see also de Swart 1998). Since the denotation of INST is characterized in terms of the information about two distinct situations at two non-overlapping successive intervals, the semantics of INST as a predicate modifier is inherently temporal. The transition between $s_{1}$ and $s_{2}$ takes place before or after the situation time of the main predicate. For example, in our initial example (1b) 'His friends brought him home drunk,' the transition from sobriety to drunkenness is located before the time when he is brought home. In (15), the INST case on 'happy' triggers the conversational implicature that Boris stopped being cheerful at some point after his birth, that is, the relevant transition is located after the situation time of the main predicate.
Boris urodilsja ${ }^{P}$ ?veselyj / veselym (i umer $^{P}$
tože veselym).
Boris was.born ?happy.NOM / happy.INST(and died
'Boris was born happy (and he also died happy).'
also happy.INST) 
This is a matter of conversational implicature, because (15) can be continued with "... and he also died happy" without a contradiction. Whether the change is located before or after the situation time established by the main predicate depends on the person, time and place deixis inherent in the main sentence's constituents, and on our general world knowledge associated with the proposition expressed, for example.

An AGR-case on a SLP depictive is obligatory, if the main clause has a progressive reading, as in (16), which is taken from Nichols (1981, p.251):

$$
\begin{aligned}
& \text { Vidiš }^{\mathrm{I}}-{\underline{\text { Ivan }_{i}}}_{\mathrm{i}} \quad \text { spit }^{\mathrm{I}} \quad \underline{\text { odetyj }}_{\mathrm{i}} \quad \text { / ?? } \text { odetym }_{\mathrm{i}} \\
& \text { see - Ivan.NOM sleeps dressed.NOM /??dressed.INST } \\
& \text { 'See, Ivan is sleeping dressed.' }
\end{aligned}
$$

In (16), the speaker intends to convey that the situation time of the main imperfective predicate and depictive are simultaneous and both situations are on-going at the speech time. On my analysis, it is predicted that the INST case must be excluded on the depictive in (16), because the evaluation time of (16) is restricted to the single present situation of the utterance, but the evaluation of the INST-predicate requires access to information about two successive non-overlapping situations, as stated in (14) above.

INST on SLP depictives is less frequent than AGR, which can be taken to support the proposal that INST is marked in the INST-AGR alternation on predicates (see (10)). ${ }^{2}$ A depictive must occur in the INST case if the main clause has an iterative or a generic/habitual reading, as (17) shows.

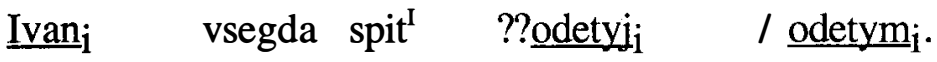

$$
\begin{aligned}
& \text { Ivan.NOM always sleeps ??dressed.NOM/ dressed.INST } \\
& \text { 'Ivan always sleeps dressed.' } \\
& \text { ALWAYS s [IN(Ivan,s) } \wedge \text { sleeps(Ivan,s)] [dressed(Ivan,s)] }
\end{aligned}
$$

In (17) the generic reading is enforced by the adverb of quantification vsegda 'always', which is the main operator in the tripartite representation that binds all the free occurrences of the variable $s$ in the formula. (17) is true iff all the situations in which Ivan sleeps satisfying the restrictive clause are also situations in which Ivan is dressed. Following Katz (1993), Chierchia (1995), Krifka et al. (1995), I use the predicate ' $I N$ ' for a maximally general locative relation that relates stages of individuals to situations in which they participate.

It has been observed by many (see Nichols 1981, p. 279, Timberlake 1982, p. 325 , Hinterhölzl 2000, for example) that predicates in generic/habitual or iterative sentences must occur in the INST case. On my account, this may be puzzling, given that SLPs retain their SL status in all case forms, and therefore always come with a situation argument that provides the variable to be bound by the relevant operator in sentential quantification over situations, as in (17). From this point of view, AGRSLPs and INST-SLPs are equally well-suited here, and yet in (17) only the INST-SLP is sanctioned. Intuitively, in (17) the property of being dressed intermittently holds of Ivan. This suggests the following analysis: Iterative (twice, several times) and generic (always, often) quantifiers can be used with predicates that have an atomic (or discrete) structure, or can be interpreted as such (cp. the process-to-event coercion in John sang three times last night). AGR-SLPs are excluded in iterative and generic contexts, because their denotation domain is non-atomic, and therefore they cannot directly serve to form the basis of quantification for iterative and generic quantifiers. The INST case, which denotes a set of pairs of situations (see (14)), one in which the property described by the predicate to which INST is attached holds and one in which it does not, generates a fluctuation in truth-value over the evaluation time of a given INSTSLP. This gives rise to a type of 'intemuptive' interpretation, and hence also to the requisite multiplicity of discrete (atomic) situations to be quantified over by the generic 
quantifier 'always'. This also means that the generic operator quantifies over sets of pairs of situations, and not just over situations.

Notice also that sentences with depictives like (17) pose the following puzzle for the mappings between syntactic and tripartite logical representations. In the logical representation of (17) the depictive 'dressed', which originates higher in the tree than $\mathrm{VP}$, if it is analyzed as an adjunct, forms the nuclear scope, while the main predicate 'sleep' in the VP contributes to the restriction (see also Krifka et al. 1995, p.43). This is problematic, if we assume Diesing's Mapping Hypothesis (1992, p.15 and elsewhere) that the material from VP is mapped into the nuclear scope and the material from IP into a restrictive clause. Interestingly, a similar problem seems to arise for postverbal adverbs and adjunct PPs in middle sentences, as in Bread cuts easily, These flowers grow in sandy soil (see Condoravdi 1989), and for adjective modifiers with non-intersective readings, as in Olga is a beautiful dancer meaning 'Olga is beautiful as a dancer' or 'Olga dances beautifully.' (For a discussion see Larson 1998.)

\subsection{ILP Depictives}

\subsubsection{ILP Depictives and the Licensing Role of the Meaning of 'Change of State'}

McNally (1993) argues that an ILP can function as a depictive if the main clause supports a conversational implicature that the individual denoted by its host argument undergoes a change with respect to the property described by the depictive. For example, the ILP intelligent in (18) is infelicitous, unless we imagine a very unlikely situation in which Fleisher switches his mental capacities on and off in some unusual way. In the most likely situation in which Fleisher has the property of being intelligent, he will be intelligent during any arbitrary stage of his life, and consequently also whenever he is playing the piano. McNally (1993, p.570ff.) argues that the temporal dependency constraint between the main predicate and depictive is then satisfied, albeit in an utterly trivial way, which makes (18) infelicitous (see also Stump 1985, Ch.VI.2.2.1.). In contrast, the use of the ILPs an immature brat and a strict authoritarian in (19) is felicitous. (19a) conversationally implicates that Boris stopped being an immature brat (just) after he joined the Army, and (19b) implicates that Boris became a strict authoritarian (just) before he left the Army. The conversational implicature defeats the default inference of persistence associated with ILPs (Condoravdi 1992), and hence the temporal dependency constraint on depictive predications is not trivially met.

(18) ??Fleisher played the piano intelligent.

(19) a. Boris joined the Army an immature brat.

b. Boris left the Army a strict authoritarian.

Following McNally's (1993) suggestions, I propose that Russian ILPs used as depictives are felicitous to the extent that they can be assigned a plausible interpretation involving a change with respect to the property they describe (see also Section 3.2.4. below). This interpretation must be overtly encoded by INST on ILP depictives, while all AGR-ILPs are systematically excluded as depictives. Examples in (20) illustrate these points. The INST-ILP depictive 'well-educated' in (20c) is acceptable, as the property of being well-educated must be acquired, but the INST-ILPs 'human being' (20a) and 'intelligent' $(20 b)$ are not. $((20 b, c)$ are taken from Hinterhölzl 2000.)

\footnotetext{
a. $\underline{\mathrm{On}}_{\mathrm{i}} \quad$ vyšel $^{\mathrm{P}} \quad \mathrm{iz}$ komnaty *čelovek $_{\mathrm{i}} \quad /$ ?? čelovekom $_{\mathrm{i}}$. he.NOM left from room *human.being.NOM / ??human.being.INST ??'He left the room a human being.'
} 

b. $\underline{\mathrm{On}}_{\mathrm{i}} \quad$ vyšel $^{\mathrm{P}} \quad$ iz universiteta $\quad \underline{u}_{\text {umnyji }} \quad$ /?? $\underline{u m n y m}_{\mathrm{i}}$. he.NOM left from university *intelligent.NOM / ??intelligent.INST ??'He left the university intelligent.'
c. $\underline{\mathrm{On}}_{\mathrm{i}} \quad$ vyšel $^{\mathrm{P}} \mathrm{iz}$ universiteta *xorošo obrazovannyji ${ }_{\mathrm{i}}$ x. obrazovannym $\mathrm{m}_{\mathrm{i}}$. he.NOM left from university *well-educated.NOM / well-educated.INST 'He left the university well-educated.'

\subsubsection{ILP Depictives and Consequences for the ILP-SLP Distinction}

With respect to Russian INST-marked ILPs I have so far proposed the following: Applying the INST case to inherent ILPs does not affect their IL status (Section 2.1.), the semantics of INST is characterized in terms of the reversal of a truth value of a predicate to which INST is applied (14), and INST on ILPs licenses the use of ILPs as depictives (Section 3.2.1.). My proposal converges with independent results of McNally (1993) and Fernald (1994/2000) with respect to English ILP depictives. We agree that a sentence with an ILP depictive is acceptable to the extent that it can be assigned a plausible reading that involves a change with respect to the property described by the ILP depictive. Nevertheless, interpreting an ILP depictive in this way does not mean that it is coerced into a SLP. McNally (1993) justifies her countercoercion stance by pointing out that defeating the default inference of temporal persistence associated with ILPs by the conversationally implicated change of state does not yield interpretations under which ILP depictives necessarily hold temporarily (as also suggested by Higginbotham p.c. in McNally 1993), that is, ILPs do not shift into SLPs. Consider (19a), for example: Suppose that Boris joined the Army when he was eighteen years old. If he stopped being an immature brat some time after joining the Army, as is conversationally implicated, then for eighten years at least he was an immature brat, which certainly was not a temporary property of Boris.

According to Fernald (1994/2000, p.31ff.), a changed state can be expressed by a SLP or an ILP, since stative predicates are SLPs (e.g., healthy) or ILPs (e.g., an immature brat). The change itself can be characterized as a reversal in the truth value of a stative proposition, and reversing the truth of a stative proposition does not require the IL and SL status of its main predicate to change. Let us take (19b) that conversationally implicates that Boris underwent a change from the state described by $\neg$ STRICT AUTHORITARIAN to the state described by STRICT AUTHORITARIAN. Most importantly, the reversal of a truth value of the stative ILP STRICT AUTHORITARIAN does not affect its IL status. Notice also that Fernald correctly observes that both SLP and ILP depictives have the interpretation of the result of a change of state, and not just ILP depictives, as McNally (1993) argues. This is also evident from the Russian examples discussed so far. However, ILPs do not always have the interpretation of the result of a change of state, as (19a) or (15), for example, show, contrary to Fernald.

The claim that ILPs used as depictives retain their inherent IL status has two important theoretical implications. First, we must reject the requirement that depictives be (interpreted as) SLPs (see Rapoport 1991, p.166, 183, and references therein), and similar earlier claims that depictives describe (potentially) transitory properties (see Section 1.). Second, the ILP-SLP distinction cannot be a purely temporal distinction. This follows assuming that ILPs as depictives involve an interpretation that crucially relies on the notion of a 'change', which is an inherently temporal notion. The clearest evidence comes from Russian, where this interpretation must be marked with the INST case on ILPs. Since INST-ILPs do not generally display distributional properties of SLPs, but rather of ILPs, applying INST to ILPs does not coerce ILPs into SLPs (see Section 2.1.). The semantics of INST is characterized in terms of a reversal in the truth value of a predicate, as I propose in (14). Assuming that the 
notion of a 'change' can be generally characterized in this way, the inherent IL or SL status of a predicate is not affected if it is interpreted as involving a change with respect to the property it expresses (see Fernald 1994/2000). If it is correct that the semantics of INST is inherently temporal, because the notion of a 'change' and its formal definition in (14) are, and INST occurs on both ILPs and SLPs, then we may conclude that the ILP-SLP distinction cannot be purely temporally based.

This conclusion supports Carlson's (1977) original view of the ILP-SLP distinction as not grounded in temporality. It also contributes to arguments against the type-theoretical ILP-SLP distinction, according to which SLPs have a spatio-temporal argument in their argument structure, while ILPs do not (see Kratzer 1989, 1995). Moreover, the semantics of the INST case (see (14)) and the behavior of INSTmarked ILPs can be also viewed as supporting independent proposals that SLPs and ILPs have a position for a situation, or spatio-temporal, argument in their argument structures (see Parsons 1990, de Swart 1991/1993, Chapter 6.1, Chierchia 1995, among others; see also related views of Enç 1986, Condoravdi 1992, McNally 1993, Musan 1995/1997, 1999, Larson 1998.) Such proposals also fit well with Rothstein's (2000) constraints on depictives given in (11). The advantage of her formulation is that she does not specifically restrict depictives to SLPs, but requires that a relation be established between the main predicate and depictive via their respective situation arguments.

\subsubsection{ILPs as Inherent Generics}

Following Parsons (1990) and others, Chierchia (1995) proposes that all predicates have a situation argument, but in ILPs this argument is bound by a generic operator. In this sense, ILPs are inherently generic. The meaning of the ILP intelligent is given in (21):

$$
\lambda x \text { GEN } s[\mathrm{IN}(\mathrm{x}, \mathrm{s})][\text { intelligent }(\mathrm{x}, \mathrm{s})]
$$

Chierchia 1995:199

It is rendered in the form a tripartite structure, which is independently motivated for the quantificational structure of sentences (see Carlson and Pelletier 1995, Krifka et al. 1995, Partee 1991a,b, 1995, and references therein). The existence of the generic operator GEN is independently motivated for the analysis of generic sentences in Krifka et al. (1995) (see also references therein). The restriction on the GEN operator ' $\mathrm{IN}(\mathrm{x}, \mathrm{s})$ ' is intended to capture the intuition that the property described by the ILP is tendentially stable through time, which in turn triggers a presupposition that there is at most one state of the type described by a given ILP whose duration occupies at most one significant portion of an individual's lifespan (Chierchia 1995, p.216). (But notice that there are ILPs like be famous describing properties that need not occupy any portion of an individual's life-time in the ordinary sense.) The nuclear scope consists of the extensional predicate 'intelligent(x,s)' that has the type of a two-place relation between individuals and situations. Nominal ILPs that function as restrictors in quantified DPs in argument positions have a variant of the type of a one-place predicate, which Chierchia (1995) represents as $* \alpha$ : *teacher $=\lambda x$ GEN s $[\operatorname{IN}(x, s)]$ [teacher(x,s)] (p.206). A noun with the situation argument cannot occur in argument positions, because the situation argument would remain free, and the resulting structure would be uninterpretable. Although nouns in argument positions enter in temporal relations (see Enç 1981, Musan 1995/1997, 1999, for example), they cannot do so via the situation argument, because it is reserved for binding by tense and Aquantifiers (in the sense of Partee, Bach and Kratzer 1987).

Grounding the ILP-SLP distinction in semantics is motivated by its role in semantics and syntax, and most prominently by accounts of well-formedness of quantified sentences, as discussed by de Swart (1991/1993), Chierchia (1995) and 
Fernald (1994/2000) for example, which speaks against a purely pragmatically-based ILP-SLP distinction assumed by Condoravdi (1992), and following her suggestions in McNally (1993), for example.

\subsubsection{The Role of INST in Licensing ILP Depictives in Russian}

Although the analysis of the data explored here could be also cast within other frameworks that distinguish ILPs and SLPs in semantic terms, I chose Chierchia's, because it is one of the most recent and best worked out ones. Taking Chierchia's (1995) view of ILPs as inherent generics and Rothstein's (2000) analysis of depictives, the Russian sentence (2) 'He left the room a murderer' with the ILP depictive 'murderer' in the AGR (here NOM) case has the logical representation in (22). Notice that if the main right conjunct is true of some situation $s_{1}$ in the actual world, it will be true of every situation temporally contained in $s_{2}$. In general, if the truth of a generic statement is supported by one situation in a world, it must be supported by all (see Kratzer 1989, 1995). Therefore, in (2) the ILP-NOM depictive 'murderer' cannot narrow down in any way the time when he left the room, which results in the oddity of (2).

$$
\begin{aligned}
& \text { (22) }[=(2)] \exists s \exists s_{1} \exists s_{2}\left[\left[s=s_{1} \oplus s_{2} \wedge \text { left-the-room(he, } s_{1}\right)\right] \\
& \left.\left.\left.\wedge \text { GEN s} s_{2}\left[\tau\left(s_{1}\right) \leq \tau\left(s_{2}\right) \wedge \text { IN }\left(\text { he, } s_{2}\right)\right] \text { [murderer(he, } s_{2}\right)\right]\right] \\
& \text { (23) }[=(2)] \exists s \exists s_{1} \exists s_{2} \exists s_{3}\left[s=s_{1} \oplus s_{3} \wedge \text { left-the-room (he, } s_{1}\right) \wedge \text { GEN } s_{2}\left[I N\left(h e, s_{2}\right)\right]
\end{aligned}
$$

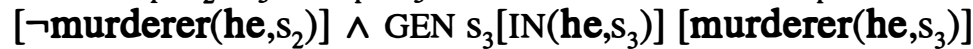

$$
\begin{aligned}
& \left.\wedge \operatorname{BEFORE}\left(\tau\left(s_{2}\right), \tau\left(s_{3}\right)\right) \wedge \tau\left(s_{1}\right) \leq \tau\left(s_{3}\right)\right]
\end{aligned}
$$

As a first approximation, the variant of (2) with the ILP depictive 'murderer' in the INST case can be represented as in (23). (23) is true in a situation which involves a single change of state, which divides the life of the individual into two consecutive portions, one in which the state of 'being a murderer' is false $\left(s_{2}\right)$ and one in which it is true $\left(s_{3}\right)$. The situation $s_{3}$, the result of a change of state, contains the situation time of the main predicate $s_{1}$ 'left the room'. The change from $s_{2}$ to $s_{3}$ is understood as having taken place just before the situation time of the main predicate, which is sufficient to narrow down the situation time of the main predicate, and in general to guarantee the satisfaction of the temporal dependency constraint on depictives, given in (11a), in a non-trivial way. Consequently, (2)/(23) with the INST-ILP depictive is felicitous. This view of ILP depictives is fully compatible with Chierchia's (1995) view of ILPs as inherent generics: They trigger a presupposition that there is at most one state of the type described by a given ILP, and whose duration occupies at most one significant portion of an individual's lifespan, however, not necessarily the whole lifespan of an individual.

In addition to the licensing condition on ILP depictives that is based on a conversationally implicated change, as McNally (1993) argues, we also need the stronger notion of an entailed change for both Russian and English. In $(2) /(23)$ the relevant single change of state is entailed, rather than being conversationally implicated. According to native informants, under one of the most salient interpretations of (2) with the INST-ILP 'murderer', (2) cannot be continued with something like "... but nothing happened in the room to make him a murderer" without a contradiction, even if the individual denoted by the subject argument had (already) been a (convicted) murderer once prior to this occasion. A good English example is Alice $_{i}$ met the White Rabbit $\underline{\text { tall }}_{i}$, that is felicitous in the context of Alice in Wonderland, for instance, where Alice is always changing her height (see Jackendoff 1990 , p.203). Under this interpretation, continuing the above sentence with “... because Alice was indeed quite a tall girl, tall with respect to everybody she met and 
anywhere she went" is at least very odd, if not impossible. This means that the above sentence supports the entailment that Alice changes her height before meeting the White Rabbit.

It may also be necessary to relativize the interpretation of ILP depictives, but also of SLP depictives, to possible worlds under consideration in discourse. The Russian sentence (24) and its English translation, for example, do not conversationally implicate that the individual denoted by the subject argument became young just before the situation time of the main predicate 'died' or stopped being young just after that time. McNally (1993, p.565) concludes that ILP depictives that occur in sentences whose main predicates express birth or death are exceptional in this respect.

$\begin{array}{lll}\mathrm{On}_{\mathrm{i}} & \text { pogib }^{\mathrm{P}} & ? / * \text { molodoji }_{\mathrm{i}} / \underline{\text { molodym }}_{\mathrm{i}} \\ \text { he.NOM died } & \text { ?/*young.NOM / young.INST } \\ \text { 'He died young.' } & \end{array}$

At the same time, it does not make much sense to interpret (24) as involving an entailment of a change into the state of being young (before or after dying). But then, the obligatory use of the INST case on the ILP 'young' is puzzling, and would seem to be exceptional on my account, as well. One possible solution would be as follows: By stating (24) the speaker asserts that 'he' died young, and conversationally implicates that (s)he expected that 'he' would die in some possible world that minimally differs from the actual world in at least one respect: namely, that 'he' is not young, because he underwent a change with respect to this property. This type of meaning is intensional and requires access to possible worlds.

To summarize, I have so far (tentatively) identifed three types of meanings involving the notion of a 'change' that are implicated in the felicitous use of depictives, each of which must be overtly marked by the INST case on ILPs and SLPs used as depictives in Russian: (i) A predicate entails that the individual it is predicated of undergoes a change with respect to the property it describes (ex. (2) and Alice met the White Rabbit tall); (ii) a predicate conversationally implicates that the individual it is predicated of undergoes a change with respect to the property it describes (ex. (15) and (19a,b)); (iii) a predicate conversationally implicates that the individual it is predicated of should not have the property described by the INST-predicate in the actual world, because it should have undergone a change with respect to this property, but did not (ex. (24)). It could also be proposed that (i)-(iii) exhibit a partial ordering according to their strengths, with (i) being the strongest and (iii) the weakest. The selection of the appropriate meaning in a given context will be determined by a general interpretive principle, approximately as follows: 'Choose the strongest meaning that is consistent with the sentence-internal, discourse-level linguistic context and with information inferred from the general background of an utterance.' (For a similar rule of interpretation see Krifka's pragmatic rule (1996, p. 146), and the Strongest Meaning Hypothesis proposed for meanings of the reciprocal quantifier by Dalrymple et al. (1994 and 1998). However, the latter is not conceived of as a pragmatic rule of interpretation.)

In the rest of this paper, I will discuss two other frequent uses of secondary predicates in Russian: namely, situation anchors and restrictors in a quantificational structure of sentences. The main differences between the two follow from the representation of quantificational sentences in terms of a semantic partition into the restrictive clause and nuclear scope as well as from Diesing's (1992) Mapping Hypothesis: (i) Situation anchors have a conjunctive interpretation with the main clause and are mapped into the nuclear scope; (ii) restrictors can be understood as an antecedent of an implicit conditional and are mapped into the restrictive clause of an explicit operator in the main clause or some implicit operator. 


\subsection{Situation Anchors}

Situation anchors are associated with a presupposition that there is at most one situation of the type described by them. Its duration covers at most one salient portion of the life-time of an individual denoted by the host argument and includes one or more occurrences of the situation described by the main predicate. In the simplest terms, and as examples in (25) show, situation anchors roughly correspond to ordinary temporal when-clauses or temporal as-clauses.
a. $\underline{\operatorname{vvan}}_{\mathrm{i}}$ odinokiji / odinokim $_{\mathrm{i}}$ napisal $^{\mathrm{P}}$ Ivan.NOM alone.NOM / alone.INST wrote
'When he was alone, Ivan wrote his best verses.
lučšie svoi stixi. best his verses

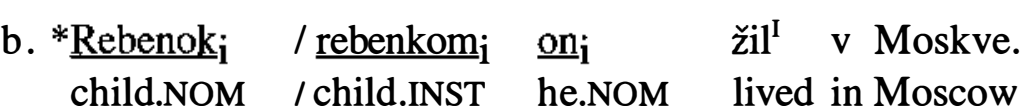
'When he was a child, he lived in Moscow.'

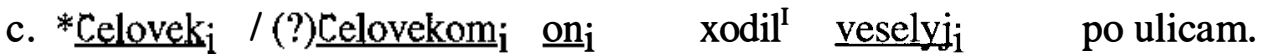 *man.NOM / (?)man.INST he.NOM walked happy.NOM along streets (?) 'When he was a human being, he walked along the streets happy.'

Sentences in (25) contain no quantificational operator that would induce a semantic partition of their content into a restrictive clause and a nuclear scope. Therefore, all the material in a sentence is mapped into a single existentially closed nuclear scope (see standard Discourse Representation Theory proposals, and also some independently made suggestions by Partee 1995, pp.567-8.) To illustrate this point, a sentence like (25a) with the SLP situation anchor 'alone' will have the simplified logical structure given in (26).

(26) $[=(25 a)] \quad \exists s$ [Ivan was alone in $\mathrm{s} \wedge$ Ivan wrote his best verses in s]

(26) shows that situation anchors have a conjunctive interpretation with the main clause. (26) means that Ivan was alone and wrote his best verses. The existential closure quantifier $\exists$ is an unselective operator that ranges over the whole nuclear scope and binds all the free occurrences of the situation variable $s$. Strictly speaking, this guarantees that the situations denoted by the main and secondary predicate occupy exactly the same interval. However, the Russian sentence (25a) also allows for looser interpretations. For example, it is also true if Ivan's writing of his best verses took up only a small portion of the whole time of his being alone. This type of reading would require some refinement of the logical structure (26).

As examples $(25 \mathrm{~b}, \mathrm{c})$ show, nominal ILPs used as situation anchors require the INST case (see also Nichols 1981, p. 150, and elsewhere). On my analysis, this follows from the semantics of INST-AGR alternation on predicates proposed here (see (10) and (14)), and also from Chierchia's (1995) view of ILPs as inherent generics. The logical representation of (25b) with the ILP in the AGR case, here NOM, can be rendered as in (27):

$$
\begin{aligned}
{[=(25 b)] } & \exists s_{2}\left[\text { live-in-Moscow }\left(\text { he, } s_{2}\right) \wedge \text { BEFORE-NOW }\left(s_{2}\right)\right. \\
& \left.\wedge \text { GEN } s_{1}\left[\tau\left(s_{2}\right) \leq \tau\left(s_{1}\right) \wedge \text { IN }\left(\text { he, } s_{1}\right)\right]\left[\text { child }\left(h e, s_{1}\right)\right]\right]
\end{aligned}
$$

Since the situation variable $s_{1}$ is introduced as an argument of the ILP 'child', it is bound by the generic operator GEN in its lexical representation and inaccessible for binding by higher operators. Therefore, existential closure quantifier $\exists$ can only bind the situation variable $s_{2}$ that is introduced as an argument of 'live in Moscow'. Consequently, the situation of the anchor ILP 'child' is possibly unrelated to the 
situation time of the main predicate 'lived in Moscow': (27) says that he is a child and he lived at some point in the past in Moscow. The anchor ILP-AGR 'child' in (25b) does not contribute possibly anything to specifying the time of his living in Moscow, and hence (25b) with the ILP-AGR 'child' is ill-formed.

Intuitively, (25b) would be naturally asserted of somebody who is believed to be no longer a child. Notice that this situation matches the conditions for the use of the INST case on predicates, as specified in (14). More precisely, I propose that the INST case here sanctions the use of the ILP 'child' as a situation anchor, because it triggers a conversational implicature that 'he' underwent a change from being a child to not being a child. Thus, the effect of INST on ILPs is to carve some salient portion out of the individual's life-time, and to narrow down the evaluation interval of the ILP. This is sufficient to spatio-temporally locate the situation time of the main predicate, and hence to guarantee the felicitous use of the whole sentence. Nevertheless, this does not mean that INST here coerces the ILP 'child' into a SLP, because the predicate 'child' still behaves like an ILP in the relevant respects: It takes arguments that are of the IL sort and describes a disposition for having stage-properties of a certain kind, and this disposition is independent of specific situations (or spatio-temporal locations), because it holds at any moment during the whole interval of its truth.

Since SLPs denote sets of temporally and spatially bounded stages of individuals (Carlson 1977), for a SLP to be felicitously used as a situation anchor, it need not take INST to narrow down the situation described by it to some salient portion of an individual's life. This may motivate a certain preference for SLPs, mainly adjectives, to agree with their controlling argument, as we have already seen in (3a) (see also Nichols 1981, p. 150, and elsewhere). However, an INST may be used if the speaker intends to convey that a change with respect to the SL property took place before or after the situation time of the main predicate. With ILPs used as situation anchors, INST is obligatory, as $(25 \mathrm{~b}, \mathrm{c})$ show. As in other cases when INST-marked predicates are used, an INST-ILP used as a situation anchor will be felicitous if it can be assigned a plausible interpretation involving a change of state. (25c) is infelicitous, in both its available readings: (i) it is uninformative in its most natural interpretation that he is dead now, but he was a human being while he was alive; (ii) it is odd if he is still alive but no longer a human being. That (25c) is infelicitous follows, given that in the most natural circumstances ILPs like be a human being (or have green eyes, be gifted) express states whose duration covers the whole life-time of an individual.

\subsection{Restrictors in a Quantificational Structure of Sentences}

Secondary predicates used as restrictors in quantificational sentences are exemplified in sentences in (28) that involve generic quantification over situations. Here, secondary predicates, the SLP 'hungry' and the ILP 'teacher' roughly correspond to atemporal when-clauses (Carlson 1979), or restrictive if/when-clauses (Farkas and Sugioka 1983), and also to restrictive as-clauses (Katz 1993) in English. They serve to restrict the domain of situations relevant for the evaluation of the main clause to those that satisfy the secondary predicate. The function of Russian secondary predicates as restrictors has so far gone unnoticed, apart from a few remarks in a recent paper by Demjjanow and Strigin (1999).
a. *Golodnyji
/ golodnymi
$\underline{\text { on }}_{\mathbf{i}}$ vozvraščalsja'
domoj.
*hungry.NOM / hungry.INST he returned
home
'Whenever he was hungry, he returned home.' 


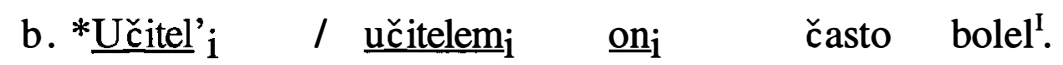
*teacher.NOM / teacher.INST he.NOM often be.ill.PAST
'He was often ill as a teacher if/when he was a teacher.'/'As a teacher, ...'

Assuming a tripartite structure for the representation of quantificational sentences, a simplified logical representation of (28a) can be given as in (29):

\section{(29) $[=(28 a)] \quad$ GEN s $[\operatorname{IN}(h e, s) \wedge \operatorname{hungry}(h e, s)][$ returned-home $(h e, s)]$}

The main predicate is mapped into a nuclear scope. The adjoined secondary predicate is mapped into the restrictive clause of the generic operator GEN, which functions as an unselective binder that binds all the free occurrences of the variable $s$ in the formula. In evaluating (29), we consider only those situations in which 'he' is hungry in determining whether 'he' returned home. (29) expresses that some proportion of situations in which he is hungry are situations in which he returned home.

At the outset it was observed that SLPs and ILPs that function as restrictors of quantifiers are constrained to occur in the INST case. $(28 \mathrm{a}, \mathrm{b})$ follow this pattern, as well. The line of reasoning for motivating the obligatory INST case here is essentially the same as proposed for INST-SLP depictives in generic sentences (see ex. (17)): AGR-predicates are excluded here, because their denotation domain is non-atomic, and therefore they cannot directly serve to form the basis of quantification for generic quantifiers. In (28a), the INST case together with the implicit generic quantifier induce a type of 'intermittent' or 'interruptive' reading of the INST-marked SLP, and consequently also the requisite multiplicity of discrete (atomic) situations to be quantified over by the generic quantifier.

While with INST-marked SLPs this type of 'intermittent' reading is unproblematic, with INST-marked ILPs, as in (28b), it poses quite a few puzzles. The generic quantifier GEN here ranges over separate situations in which he is a teacher, and the sentence expresses that some proportion of these situations are situations in which he was often ill. A similar type of 'intermittent' reading of ILPs can be also found in combinations of ILPs with quantificational adverbs in English, as in (30) discussed by Fernald (1994/2000), for example:

\section{a. Max is sometimes a California resident.}

b. Francis is occasionally blond.

Following Carlson's (1977) approach, Fernald (1994/2000) convincingly argues that this type of an 'intermittent' reading of ILPs is not a matter of coercion into SL interpretations, because the predicates California resident and blond here take arguments that are of the individual sort. Similarly, in Russian, ILPs in the INST case that are used as restrictors in generic sentences like (28b) retain their IL status, although they are used with apparently SL interpretations. Here, the property of being a teacher in a given situation is a property of the $\mathrm{IL}$ sort. Although it does not apply to the whole or even most of the individual's life-time, it is not restricted to a specific stage of the individual in so far as it is still independent of specific temporal and spatial locations. Therefore, INST is best not to be treated in terms of a semantic function that maps ILPs into SLPs by removing, for example, the GEN operator binding the situation variable in the semantic representation of ILPs. This sheds doubts on a proposal along these lines made by Katz (1993) for ILPs that occur in generic asclauses like As an advisor, Gloria is reliable. As is here interpreted as a function that takes a generic property $P$ and returns the SL correlate of $P$.

If it is correct that ILPs form the restrictive clause in sentential quantification over situations, then we face two main problems: One concerns the denotation of ILPs in this function, and the other the expression of quantification in relation to quantificational ontology. First, on Chierchia's view of ILPs as generics (as on most 
other current views of ILPs), sentences like (28b) would be ruled out as ungrammatical. This follows given that the generic quantifier GEN binds the situation variable of ILPs (see (21)), and therefore makes it unavailable for binding by higher operators. This also means that quantifiers that have ILPs as restrictors can only bind their individual variables, as in Oranges are often sweet. However, this view of ILPs turns out to be too restrictive, and needs to be modified. Not all ILPs are associated with the presupposition that there is at most one state of the type described by a given ILP, and whose duration occupies at most one significant portion of an individual's life-time, as Chierchia (1995, p.216) states it, and also similarly de Swart (1991/1993, p.65) in her uniqueness presupposition on the Davidsonian argument. There is also a significant number of ILPs describing states that may occupy more than one significant portion of an individual's life-time. Examples include nominal ILPs that describe occupations like teacher, director, jockey, social positions, status including distinctions like gold medallist, kinship terms like husband, or residency and citizenship like California resident andGerman citizen. It is, therefore, not surprising that we find nominal ILPs of this type with an 'intermittent' or 'interruptive' reading, as in (30), or in (28b), where they are used as restrictors in sentential quantification over situations. In short, we need to formulate an adequate denotation for such ILPs that captures their IL status (by keeping Chierchia's insight that they are inherently generic, for example) as well as the observation that they may exhibit an 'interruptive' reading, when used as restrictors, for example. Such ILPs need to be distinguished from other types of ILPs that satisfy de Swart's and Chierchia's uniqueness presupposition on the situation argument, and therefore block quantification over situations. These include ILPs like be a human being, have green eyes and be gifted that express states whose duration covers the individual's life-time; child, adult, young, old that describe 'once-only' maturation stages of individuals; or be a great poet that expresses a property that may extend beyond the life-time of an individual. Finding the appropriate denotation(s) for ILPs that would cover all their different types and uses must remain a topic for future research.

Second, Partee (1991a) proposes that D-quantifiers (mainly 'determiner' quantifiers) tend to range over individuals, while A-quantifiers (including adverbial quantifiers and the generic GEN often range over events or situations. ('Dquantification' and 'A-quantification' are here used in the sense introduced by Partee, Bach and Kratzer 1987.) However, adverbial quantifiers can quantify over individuals, when they are combined with ILPs, as in Oranges are often sweet (see Lewis 1975, Heim 1982, Partee 1991a,b; specifically for generic quantifiers see Filip 1994, Dobrovie-Sorin 2000). However, (28b) does not fit such typical patterns: Here, we have the generic quantifier GEN, an A-quantifier, whose restriction is formed with the ILP 'teacher', and yet the quantification does not concern individuals, that is, a set of teachers, but rather a set of individual situations in which it is true of a single individual that he is a teacher. Given that A-quantifiers constitute a large and heteregeneous class with respect to their formal expression, potential to function as selective or unselective binders, it may not be surprising that they also differ from one another with respect to their range and how what they quantify over is determined (see Partee 1991b, 1995). Among the factors that are implicated here are the overt phrase structure, the topic/focus structure, the presence of an ILP or a SLP in their restrictive clause, and we may also add the type of an ILP in the restriction (see the previous paragraph). This situation also points to the question about the systematic division of A-quantifiers along such parameters, already posed by Partee (1991a,b, 1995). As far as the future research is concerned, we also need to specify the conditions under which ILPs are used with A-quantifiers to express quantification over situations, and in the light of such data rethink the relation between the expression of quantification and quantificational ontology. 


\section{Conclusions}

The INST-AGR alternation explored here provides new evidence in support of Carlson's (1977) original view that the ILP-SLP distinction is not based in temporality, and in support of adding a situation argument, or a spatio-temporal argument, to every predicate, as Parsons (1990) proposes. I argued that Russian predicative nouns and other inherent ILPs retain their IL status, regardless in which case they are realized, and even if they obligatorily occur in the INST case with apparently SL interpretations: namely, when used in secondary predications as depictives, situation anchors, and restrictors in sentences expressing quantification over situations. The semantics of the INST case, the marked case in the INST-AGR alternation, is crucial in licensing ILPs as secondary predicates. It expresses the meaning of a 'change' with respect to the property described by a predicate to which it is applied. This has the effect of (i) narrowing down the evaluation times of INSTmarked ILPs, which guarantees the felicitous use of ILPs as depictives and situation anchors, or of (ii) generating an 'interruptive' interpretation of INST-marked ILPs, and, therefore also a multiplicity of situations to quantity over by some quantificational operator.

Among the many topics for future research, apart from those already mentioned, let me briefly mention the following three: First, the behavior of secondary predicates under negation. Only depictives may fall within the scope of negation of the main verb, while situation anchors and restrictors never do. For restrictors and depictives this difference directly follows from my analysis: The semantic content of restrictors is presupposed, and therefore it does not fall into the scope of negation, while the semantic content of depictives is not, and hence may be caught up under the scope of negation (depending on the focus structure). Second, the syntactic and semantic motivation for the co-occurrence constraints on different types of secondary predicates. Since depictives can co-occur with situation anchors and restrictors, they are clearly independent of both types of predicates, while situation anchors and restrictors are in complementary distribution. Third, the role of morphological case as a formal and semantic licenser of secondary predicates, and ILPs in particular. One question here regards the similarities and differences in licensing of secondary predicates by morphological case systems (see Rapoport 1991 on Warlpiri, for example).

\section{Endnotes}

* I would like to thank Gregory Carlson, Chris Kennedy, Amim von Stechow, and audiences at the workshop on Predicative Constructions at Zentrum für Allgemeine Sprachwissenschaft in Berlin (Germany), colloquia at Northwestern University, the University of Chicago, the University of Tübingen, and at the conference on Formal Approaches to Slavic Linguistics at the University of Michigan.

1. See Nichols (1981) and Timberlake (1982), for example.

2. Timberlake (1982, p. 329) observes that AGR (nominative case in his examples) on a depictive is used in $77 \%(23 / 30)$ of the examples with a perfective main verb he collected.

\section{References}

Bach, E. 1981. “On Time, Tense, and Aspect: An Essay in English Metaphysics.” P. Cole (ed.). Radical Pragmatics. New York: Academic Press. Pp. 63-81.

Bach, E. 1986. “The Algebra of Events." Linguistics and Philosophy 9, 5-16. 
Becker, M. 2000. "The syntactic structure of predicatives: Clues from the omission of the copula in child English." Handout from the workshop on Predicative Constructions. Berlin, ZAS.

Bresnan, J. 1982. "Control and Complementation." Bresnan, J. 1982. (ed.) The Mental Representation of Grammatical Relations.

Carlson, G.N. 1977. Reference to kinds in English. Ph.D. Thesis, University of Massachusetts at Amherst. [Published 1980 by Garland Publishing Inc., New York]

Carlson, G.N. 1979. "Generics and Atemporal When." Linguistics and Philosophy 3, 49-98.

Carlson, G.N. 1982. "Generic Terms and Generic Sentences." Journal of Philosophical Logic 11, 145-181.

Carlson, G.N. and F.J. Pelletier. 1995. The Generic Book. Chicago: The University of Chicago Press.

Chierchia, G. 1995. "Individual-Level Predicates as Inherent Generics." Carlson, G.N. and F.J. Pelletier. 1995. (eds.), pp. 176-223.

Condoravdi, C. 1989. "The Middle: Where Semantics and Morphology Meet." MIT Working Papers in Linguistics 11, MIT.

Condoravdi, C. 1992. "Individual-Level Predicates in Conditional Clauses." Paper presented at the LSA meeting. Philadelphia, PA.

Dalrymple, M., Mchombo, S. A. and S. Peters. 1994. "Semantic Similarities and Syntactic Contrasts between Chichewa and English Reciprocals." Linguistic Inquiry 25, 145-163.

Dalrymple, M., Kanazawa, M., Kim, Y., Mchombo, S. and S. Peters. 1998. "Reciprocal Expressions and the Concept of Reciprocity". Linguistics and Philosophy 21, 159-210.

Demjjanow, A. and A. Strigin. 1999. "Real Adjuncts in Instrumental in Russian," ms.

Diesing, M. 1992. Indefinites. Cambridge, Mass.: The MIT Press.

Dobrovie-Sorin, C. 2000. "Unselective Binding and Genericity," ms.

Enç, M. 1986. "Towards a Referential Analysis of Temporal Expressions." Linguistics and Philosophy 9, 405-426.

Farkas, D. and Y. Sugioka. 1983. "Restrictive If/When Clauses." Linguistics and Philosophy 6, 225-258.

Fernald, T. 1994/2000. Predicates and Temporal Arguments. Oxford/New York: Oxford University Press. [PhD Thesis 1994].

Filip, H. 1994. "Quantificational Morphology." Formal Approaches to Slavic Linguistics, Volume II. The MIT Meeting 1993, Avrutin, S., Franks, S. and L. Progovac (eds.). Ann Arbor Michigan Slavic Publications, 144-177.

Geist, L. 1999. "Russisch byt' als funktionale und/oder lexikalische Kategorie." ZAS Papers in Linguistics 14, 1-39.

Hinterhölzl, R. 2000. "Semantic Constraints on Case Assignment in Secondary Adjectival Predicates in Russian." Handout from the workshop on Predicative Constructions. Berlin, ZAS.

Jackendoff, R. S. 1990. Semantic Structures. Cambridge, Mass.: The MIT Press.

Jakobson, R. 1936/71. "Beitrag zur allgemeinen Kasuslehre: Gesamtbedeutung der russischen Kasus." Selected Writings: Word and Language. The Hague-Paris, pp. 23-71.

Katz, G. 1993. "The Interpretation of As-Headed Adjuncts." WCCFL 12, 547-560.

Kratzer, A. 1989. "Stage-Level and Individual-Level Predicates." Bach, Kratzer, and Partee (eds.), Papers on Quantification, NSF Report, Amherst, Mass.

Kratzer, A. 1995. "Stage-Level and Individual-Level Predicates." Carlson, G.N. and F.J. Pelletier. 1995. (eds.), pp. 125-175.

Krifka, M. 1986. Nominalreferenz und Zeitkonstitution. Zur Semantik von Massentermen, Individualtermen, Aspektklassen. Ph.D. Thesis, The University of Munich, Germany. 
Krifka, M. 1992. "Thematic Relations as Links between Nominal Reference and Temporal Constitution." Sag, I. A. and A. Szabolsci (eds.), Lexical Matters. Stanford: CSLI, pp. 29-53.

Krifka, M. 1996. "Pragmatic Strengthening in Plural Predications and Donkey Sentences". SALT 6. Ithaca: Cornell University, pp. 136-153.

Krifka, M. 1998. "The Origins of Telicity." Rothstein, S. (ed.) Events and Grammar. Dordrecht/Boston/London: Kluwer Academic Publishers, pp. 197-235.

Krifka, M., Pelletier, J., Carlson, G., ter Meulen, A. G. B., Link, G., and G. Chierchia. 1995. "Introduction" to Carlson, G.N. and J. F. Pelletier (eds.). The Generic Book. Chicago: The University of Chicago Press, pp. 1-124.

Larson, R. 1998. "Events and Modification in Nominals". SALT 8, 145-168.

Lasersohn, P. 1992. "Generalized Conjunction and Temporal Modification." Linguistics and Philosophy 15, 381-410.

Lewis, D. 1975. “Adverbs of Quantification.” Keenan, E. L. (ed.). Formal Semantics of Natural Language. Cambridge: Cambridge University Press.

McNally, L. 1993. "Adjunct Predicates and the Individual/Stage-Level Distinction". WCCFL 12, 561-576.

Musan, R. 1995/1997. On the Temporal Interpretation of Noun Phrases. Ph.D. Thesis, MIT. [Published 1997 by Garland Publishing Inc., New York]

Musan, R. 1999. "Temporal Interpretation and Information-Status of Noun Phrases." Linguistics and Philosophy 22, 621-661.

Nichols, J. 1981. Predicate Nominals: A partial surface syntax of Russian. (University of California Publications in Linguistics 97.) Berkeley-Los Angeles-London.

Parsons, T. 1990. Events in the Semantics of English: A Study in Subatomic Semantics. Cambridge, Massachusetts and London, England: The MIT Press.

Partee, B.H. 1991a. "Adverbial Quantification and Event Structures." Proceedings of the Berkeley Linguistics Society 17, 439-456.

Partee, B.H. 1991b. "Domains of Quantification and Semantic Typology." F. Ingemann (ed.) Proceedings of the 1990 Mid-America Linguistics Conference, University of Kansas, 3-39.

Partee, B.H. 1995. "Quantificational Structures and Compositionality." Bach, E., Jelinek, E., Kratzer, A., Partee, B. (eds.) 1995. Quantification in Natural Languages. Dordrecht: Kluwer Academic Publishers. Pp. 541-601.

Partee, B.H., E. Bach, and A. Kratzer. 1987. "Quantification: A Cross-Linguistic Investigation." NSF proposal, University of Massachusetts at Amherst.

Pereltsvaig, A. 1999. Case, interpretation and clausal structure: Issues in Russian copular constructions. Dissertation prospectus, McGill University.

Rapoport, T. R. 1991. "Adjunct-Predicate Licensing and D-Structure." Syntax and Semantics 25. Pp. 159-187.

Rothstein, S. 1983. The Syntactic Forms of Predication. Ph.D. Thesis, MIT.

Rothstein, S. 2000. "Secondary Predication and Aspectual Structure." FabriciusHansen, C., Lang, E. and C. Maienborn (eds.), Approaching the Grammar of Adjuncts. ZAS Papers in Linguistics 17, 241-264.

Stump, G.T. 1985. The Semantic Variability of Absolute Constructions. Dordrecht: Reidel.

de Swart, H. 1993. Adverbs of Quantification: A Generalized Quantifier Approach. Garland. [PhD Thesis 1991].

de Swart, H. 1998. "Aspect Shift and Coercion." NLLT 16, 347-385.

Timberlake, A. 1982. "Invariance and the syntax of Russian syntax." Hopper, P. J. (ed.) Tense-Aspect: Between Semantics and Pragmatics. John Benjamins Publishing Co. Amsterdam/Philadelphia. 